\title{
Survey on the Knowledge, Attitudes, Primary Prevention Practices and Screening of Skin Cancers in Albinos in Burkina Faso
}

\author{
Smaila Ouédraogo', Nayi Zongo 2*, Nina Korsaga-Somé ${ }^{3}$, Seraphine Marie Suzanne Kaboré2, \\ Edgar Ouangré2, Maurice Zida², A. S. Ouédraogo4, Aboubacar Hierrum Bambara², \\ Augustin Touzoula Bambara², Si Simon Traoré2, Pascal Niamba², Adama Traoré2, Ahmadou Dem ${ }^{5}$
}

\begin{abstract}
${ }^{1}$ Public Health, Yalgado Ouédraogo University Hospital, Ouagadougou, Burkina Faso
${ }^{2}$ General and Digestive Surgery, Yalgado Ouédraogo University Hospital, Ouagadougou, Burkina Faso

${ }^{3}$ Dermatology and Venerology, Yalgado Ouédraogo University Hospital, Ouagadougou, Burkina Faso

${ }^{4}$ Pathological Anatomy and Forensic Unit, Yalgado Ouédraogo University Hospital, Ouagadougou, Burkina Faso

${ }^{5}$ Oncology Institute Joliot Curie of Dakar, Dakar, Senegal

Email: *Nayizongo@yahoo.fr
\end{abstract}

How to cite this paper: Ouédraogo, S., Zongo, N., Korsaga-Somé, N., Kaboré, S.M.S., Ouangré, E., Zida, M., Ouédraogo, A.S., Bambara, A.H., Bambara, A.T., Traoré, S.S., Niamba, P., Traoré, A. and Dem, A. (2016) Survey on the Knowledge, Attitudes, Primary Prevention Practices and Screening of Skin Cancers in Albinos in Burkina Faso. Journal of Cancer Therapy, 7, 812-823. http://dx.doi.org/10.4236/jct.2016.711081

Received: August 18, 2016

Accepted: October 28, 2016

Published: October 31, 2016

Copyright $\odot 2016$ by authors and Scientific Research Publishing Inc. This work is licensed under the Creative Commons Attribution International License (CC BY 4.0).

http://creativecommons.org/licenses/by/4.0/

\section{(c) (i) Open Access}

\section{Abstract}

Objective: The objective is to study the knowledge that albinos have on skin cancers, and their attitudes in terms of primary prevention and the screening practices for skin cancers in Burkina Faso. Methods: This is a cross-sectional and descriptive KAP study conducted from May $18^{\text {th }}$ to July $7^{\text {th }} 2015$. It involved albinos aged at least 12 years. Their general knowledge, prevention attitudes and screening practices were considered. Results: All the responding albinos had already heard about skin cancers. Their main source of information was health workers (65.6\%). They were showing at least two risk factors (99.2\%) but only $68.3 \%$ affirmed having already undergone screening for skin cancer. Ignorance of the existence of screening was the main obstacle to it $(16 / 26)$. The prevention means used was sun avoidance, the use of cream and protection clothing respectively in $84 \%, 41.5 \%$ and $51.2 \%$. The skin lesions found were hyperpigmented macules $(77.8 \%)$ then actinic keratosis (40.7\%) and finally cheilitis (35.8\%). We detected 4 cases of skin cancers confirmed by biopsy. Conclusion: Risk factors are frequent. Participation to screening is still insignificant. A lot is still to be done to extend the protection means. A good awareness-raising campaign and the accessibility to protection means remain for all, the best defense in the fight against skin cancers in albinos.

\section{Keywords}

Albinos, Screening, Prevention, Skin Cancers 


\section{Introduction}

Skin cancer is a major public health matter at the global level with 14.1 million of new cases in 2012 and 8.2 million deaths per cancer [1].

Skin cancers are among those that have increased the most over the past fifty years [2]. In Switzerland and in the USA, they represent $1 / 3$ of new cases [3]. In Africa, they represent between $7.5 \%$ and $11.83 \%$ of all cancers [4] [5].

Apart from albinism, the main risk factor is ionizing radiation. Albinos, due to their melanin deficiency, are more sensitive to the effects of ultraviolet rays [6]-[8]. In fact sun exposure seems to be the major risk factor in the development of skin cancers in albinos in the African countries ranked among the sunniest of the planet [6]-[9]. These cancers develop mostly on precancerous lesions such as actinic keratosis, cheilitis, burn scars and chronic wounds [10]. Protection from ultraviolet rays and the treatment of precancerous lesions help prevent the appearance of skin cancers in albinos [7].

In our context of work, many albinos having precancerous and cancerous lesions were received in consultation. The diagnosis of cancer seems late for large lesions. The treatment is mostly surgical, delicate and the life and esthetic prognosis is unfavourable. Several studies were conducted on skin cancers in Burkina Faso. However, any of them dealt with skin cancers in albinos specifically, though they constituted a vulnerable group. The "Association burkinabe pour l'intégration des personnes albinos (ABIPA)", Burkinabe Association for the Integration of Albinos was created to defend their cause. Thus, this association works towards the well-being of albinos through several activities like counseling of albinos and their families about the harmfulness of the sun and the need for protection; the organizing of dermatological consultations and the sharing of equipments to protect from the sun [11]. Despite all these efforts, albinos still seem not informed enough on skin cancer. Therefore, it appeared important to us to conduct this survey, in order to assess the knowledge, attitudes and practices of albinos before dealing with the prevention measures and the screening of skin cancers in Burkina Faso.

\section{Methodology}

Type and period of the study: We have conducted a cross-sectional and descriptive study covering the period from May $18^{\text {th }}$ to July $7^{\text {th }} 2015$.

Site of the study: Our study took place in Burkina Faso, a country located in the heart of western Africa. Its population is amounted to 16,484 in 2014 [12]. Those under 12 years represent $46 \%$ of the population. According to ABIPA which periodically gathers albinos in four sites (Ouagadougou, Bobo-Dioulasso, Banfora and Tenkodogo), the number of albinos is estimated at 500 in 2014 all over the national territory, i.e. one albinos for 32,484 inhabitants [11].

Population of the study: there was no available list of all the albinos of Burkina Faso. As there was no sampling frame, we did a convenience sampling. The method used was the "camp" method. The meeting with the albinos, in order to include them in the study, was taking place on the occasion of consultations organized for this purpose. Were included in our study all the albinos aged at least 12 years, who were received in 
consultation in the four zones of gathering that are Bobo Dioulasso, Banfora, Tenkodogo and Ouagadougou and for whom we got their informed consent or that of their parents (for minors). The expected total number of albinos meeting the conditions to be included in the study was 270 . Eighty-two came for consultation and were all included in the study.

Data collection procedure: We were able gather the albinos thanks to communicate through radio stations and by telephone calls. In each meeting site, we had a thought leader (member of the local section of the association) who was going door-to-door the days before our arrival to motivate the albinos, so that they take part in the study. We went to the four sites where the questionnaire was administered. The information was collected during interviews with the albinos. We were interested in their general knowledge of risk factors and the screening of skin cancers. Their prevention attitudes and screening practices were considered.

A pre-test was first of all given to subjects that were taking part in the study, in order to assess to validity of the questionnaire. We numbered 10 risk factors of skin cancers. Each factor found by the surveyors was noted by one point. The knowledge of risk factors was considered null or bad if the total score was equal to zero or inferior to 3 . The knowledge was considered average, when the total score was between 3 and 6 points. It was good when the total number of points was superior to 6 points.

Data treatment and analysis: The data collected were recorded manually and served to measure the variables retained for our study. The data treatment and analysis was done by computer with the French version of the software Epi Data 3.1 and then an export of the data was made on the software SPSS for a clearance and the analysis according to the subjects addressed. The construction of graphs was done by the software Excel 2007.

Ethical consideration: We got the authorization of the Ministry of Health, as well as the various administrations' leaders of the areas concerned. The albinos and those accompanying them, for minors, were informed of the objectives of the survey and their consent was requested and obtained before their participation in the study. Anonymity was respected.

\section{Results}

\subsection{General Knowledge of Skin Cancer}

\subsubsection{Sources of Information on Skin Cancer}

Eighty two (82 albinos) were interviewed, being a proportion of $30.4 \%$ compared to the total number expected. All the albinos surveyed had already heard about skin cancers. However, only $74.4 \%(61 / 82)$ could remember their first source of information. They received the information from health workers in 65.6\% (40/61) cases (Figure 1).

\subsubsection{Knowledge of Risk Factors}

All albinos surveyed in our series had answered to questions relating to risk factors of cancers. They all knew at least one risk factor and 79.3\% (65/82) had a good knowledge of risk factors (at least 6 factors were known). The long exposure to the sun was men- 
tioned as a risk factor of skin cancer in $91.5 \%$ (75/82) (Table 1).

\subsubsection{Knowledge of Precancerous Lesions}

Thirty albinos were affirming to know precancerous lesions and 20 among them (66.7\%) mentioned chronic ulcerations as precancerous lesions. Twenty-nine albinos knew that the detection and early treatment of precancerous lesions helps avoid that these lesions turn into a cancer.

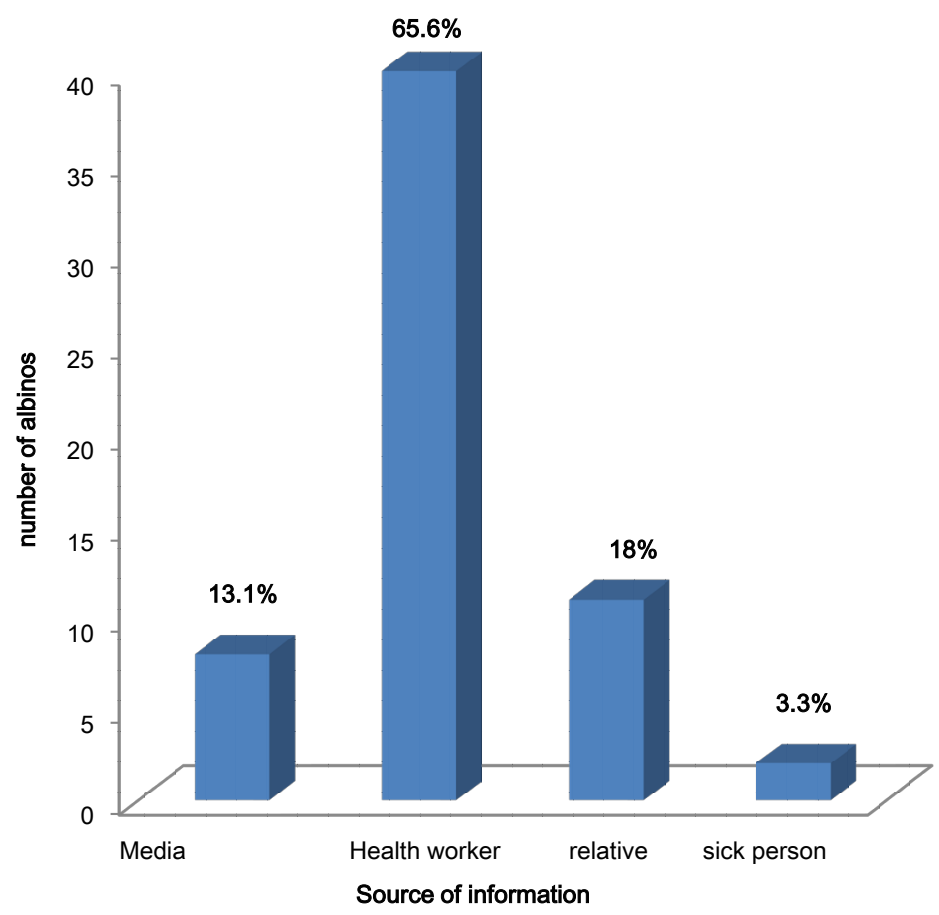

Figure 1. Distribution of albinos according to the sources of information on skin cancer.

Table 1. Distribution of albinos according to their knowledge of skin risk factors.

\begin{tabular}{cc} 
Risk factors & Number of albinos \\
\hline $\begin{array}{c}\text { Long exposure to the sun } \\
\text { Tobacco addiction } \\
\text { Occupational exposure }\end{array}$ & 75 \\
Hydroquinone/cosmetic products & 63 \\
Albinism & 75 \\
Immunodepression due to HIV & 68 \\
Antecedent of personal skin cancer & 13 \\
Burn scar & 70 \\
Hyperpigmented mark & 60 \\
Chronic wound & 43 \\
\hline
\end{tabular}




\subsubsection{Knowledge of Screening}

All the albinos interviewed talked about the frequency and the target population of the screening. Among them, 39\% (33/82) thought everybody was concerned by the screening and 33\% (27/82) thought that albinos were the most concerned by the screening of skin cancer. Moreover, $42.7 \%$ (35/82) thought that there should be a routine screening every trimester and 39\% (32/82) of albinos thought that consultation should be based on one's availability.

\subsection{Prevention Attitudes}

\subsubsection{Risk Factors Found}

The albinos included were presenting apart from albinism, risk factors in 100\% (82/82) of cases. The main risk factor presented by the albinos was sun exposure which was real in $85.4 \%(70 / 82)$ of cases. In $76.8 \%$ (63/82), the albinos were showing each at least three risk factors.

\subsubsection{Primary Prevention Attitudes}

All the albinos knew that there are primary prevention means. Seventy-five i.e. (91.5\%) of them had used at least one prevention means. To avoid the occurrence of skin cancers, $51.2 \%$ were wearing protecting clothing; $42.5 \%$ were using protecting creams and $84 \%$ were practicing sun avoidance.

\subsubsection{Secondary Prevention Attitudes}

Out of 82 albinos, $22(26.8 \%)$ had in the past precancerous lesions. Sixteen had consulted and were treated. The lesions mostly observed were hyperpigmented macules (17/22), then actinic keratosis (9/22) and cheilitis (8/22). During our study, we detected 4 cases of skin cancers ( 2 cases of epidermoid carcinomas and 2 cases of basal cell carcinomas) that were confirmed by biopsy and treated surgically.

\subsection{The Practice of Screening}

\subsubsection{Age at First Screening}

A total of 56 albinos (68.3\%) affirmed having already undergone skin cancer screening. Forty-five (54.9\%) affirmed having been screened after 12 . The age at first screening varied from 2 to 50 years. In $30.5 \%$ of cases, the first screening occurred between 12 and 21 years.

\subsubsection{Place of the First Screening}

Among the 56 albinos that had already undergone screening, $22(39,3 \%)$ had their first screening in a Health and Social Promotion Center (CSPS) (level 1), 30.3\% in a Medical Center with Surgical Unit (CMA) (level 2); $28.6 \%$ in a Dermatology Unit and $1.8 \%$ in a Cancer Department (level 3).

\subsubsection{Reasons for Non-Screening}

In our surveyed population, 26 albinos had never undergone screening for skin cancer. Among them, 12 affirmed not knowing that screening was possible. Five never did it, due to a lack of resources to pay for the consultation. Three affirmed not having unde- 
sirable symptoms that could motivate them for screening. Three affirmed not knowing a place for screening. In two cases, the distance from the health center was the reason for the non-screening.

\section{Discussion}

The high cost of such a study and the lack of financing were the limitations to our study. An appropriate financing would have enabled us spend more time in the regions, go door to door to the albinos who did not come on the consultation day. Besides, the Association of Albinos (ABIPA) would have better mobilized its members. This would have led to a better response rate.

Though figures vary, we think that in Northern America and in Europe a person over 20,000 suffers from albinism at various degrees. In Tanzania and throughout Eastern Africa, albinism is much more expanded, with about one person affected over 2000 [13]. In Burkina Faso, there are not yet reliable statistics on the number of albinos, but according to ABIPA they were about 500 in 2014, i.e. one albino person for 324,484 inhabitants [11] [12]. Only 30.4\% compared to the total number expected in theory came for consultation and were included in this study. Albinos feel stigmatized, exploited and most often they tend to hide instead of showing themselves. If not by the intervention of their peers, local leaders of their association (ABIPA), the rate of respondents would have been much lower.

All albinos surveyed were informed and aware of the existence of skin cancer. This could be explained by the real sensitization efforts of the Burkinabe Association for the Integration of Albinos (ABIPA). In fact, it carries out several activities like the counseling of albinos and their families on the harmfulness of the sun and the necessity to protect oneself, the organizing of dermatological consultations and the sharing of protecting equipments (clothes, creams). The health workers were the main source of information of albinos in our series (40/61). In Zimbabwe [6], only $11.8 \%$ of albinos had the health workers as a source of information. This could be explained by the collaboration existing between health workers and ABIPA in Burkina Faso during awareness-raising and free consultation campaigns. The provision of enough means to this association would make it more efficient all over the territory and would form real barrier to skin cancer in Burkinabe albinos exposed to several risk factors.

All the albinos surveyed (82/82) answered to the questions relating to risk factors. All of them knew about at least one risk factor and the long exposure to the sun was the most mentioned (75/82). Similar results were noted in the literature (100\%) [6]. Melanin is a real filter that protects from sunrays. Albinism is the privation from the protecting melanin [14]. The skin of albinos is therefore particularly fragile to sunrays [7]. Our results clearly show that albinos are well-informed about the risk factors they are confronted with and mostly about the harmful effect of the sun on the skin. Despite all, there is still the need to organize awareness-raising and screening campaigns.

All the albinos (82/82) talked about the frequency of screening and the target population. Albinos are a risk group for skin cancer and must benefit from a routine screening 
[2]. In our study, several albinos are not aware of their predisposition to skin cancers and did not see the interest of screening for albinos especially. Routine screening every 3 months is the appropriate practical attitude to adopt [2]. This practical attitude was recognized by a proportion of $42.7 \%$ (35/82) only in our study. It is therefore important to organize regular screening campaigns, if possible by region and mostly make them affordable for albinos.

The albinos had a good knowledge of risk factors, but could not protect themselves efficiently. The majority of the albinos had at least three risk factors in our series. The main risk factor found, apart from albinism was the long exposure to the sun (85.7\%). Skin cancer is the main cause of death associated with albinism and sun exposure associated with albinism is the main risk for skin cancer [8] [9] [15]. The long exposure to the sun was the main risk factor for cancers in albinos in other sunnier countries like Nigeria (75\% of albinos) [16] and Zimbabwe (100\%) [6]. Like in Burkina Faso, most of albinos as the rest of the population live on farm work and are therefore very exposed to the sun. These living conditions complicate the prevention of which the best attitude is sun avoidance. Some albinos (84\%) were using sun avoidance once in a while as a means of protection.

The other means of protection such as solar creams and clothing were less used because of their unaffordability. This situation is similar to that of other African countries. In fact many albinos were not wearing hats and most of them were even wearing short-sleeve shirts [7]. There is need for awareness-raising and a distribution of protecting creams and long-sleeve shirts to all albinos.

\section{Screening Practices}

Only 56/82 of albinos affirmed having undergone screening for skin cancer. Most of them i.e. 22/56 had their first screening in a CSPS. Mabula [8] in Tanzania had noted that $71.9 \%$ of patients having precancerous and cancerous lesions were consulting and treating their pathology firstly in peripheral health centers. This could be explained by the arrangement of our health systems, which consists in consulting first in peripheral health centers, in accordance with the directives of the Alma Ata Conference [17]. The ideal would be to form the agents of peripheral health centers (nurses) in the detection of suspicious lesions on skins of albinos coming for screening. In the reasons for nonscreening 12/82 albinos affirmed not knowing that screening was being done. To do this, the information should be given to a greater number of people through the organizing of more awareness-raising campaigns and the drawing of the list of all the albinos of Burkina Faso, in order to better disseminate the information.

The screening of precancerous lesions is one the bedrocks in the fight against skin cancer in albinos. It is effective, because its evolution towards a cancer is long [7] [18] [19]. The marks of the evolution towards skin cancers appear on the albinos from their first anniversary. The subclinical malign transformations were already present at 20 years and the cancer was becoming invasive, diffuse and leading to death in the third or fourth decade. Four successive stages which can be detected were therefore established. 
Stage 1 is represented by a burn. Stage 2 is marked by skin atrophy. Stage 3 corresponds to solar keratosis and stage 4 to clinical carcinoma [7].

\section{Conclusion}

Most of the albinos had a good knowledge of risk factors. However, many of them were accumulating several risk factors. The most used prevention measure was sun avoidance. Routine screening of cancer was not respected by all the albinos and the main reason raised was the ignorance of the existence of routine screening and its necessity. The corollary is the several precancerous lesions found in the albinos of our study. We have also found cases of cancer or antecedents of cancers. Sun avoidance remains the most effective method against sunrays, but the most difficult in countries like Burkina Faso where people live on farming. A more effective fight against skin cancer in albinos in Burkina Faso goes through the building of ABIPA's awareness-raising capacity, the availability of protection means like clothing and protecting creams. In addition, health workers should make of each consultation an opportunity for screening.

\section{References}

[1] Organisation Mondiale de la Santé (2013) Dernières statistiques mondiales sur le cancer. Communique de Presse $\mathrm{N}^{\circ} 223$ du 12 décembre. https://www.iarc.fr/fr/media-centre/pr/2013/pdfs/pr223_F.pdf

[2] Basset-Seguin, N., Dreno, B. and Grob, JJ. (2002) Tumeurs cutanées épithéliales et mélaniques Carcinomes épithéliaux. Annales de Dermatologie et de Vénéréologie, 129, 2S132-2S136.

[3] Bulliard, J.L., Levi, F. and Panizzon, R.G. (2009) Epidémiologie des cancers épithéliaux de la peau. Revue Médicale Suisse, 5, 882-888.

[4] Aquaron, R., Baden, C., Bergé-Lefranck, J.L., Mansion, P., Mattei, J.F. and Philip, N. (2004) L'albinisme oculocutané au Magheb: A propos de 15 observations en Algérie, au Maroc et en Tunisie. Antropo, 7, 55-61.

[5] Pitche, P., Tchamdja, S., Napo-Koura, G., Bakonde, P., Kpodzro, K. and Tchangai-Walla, K. (1997) Les cancers cutanés en consultation dermatologique à Lomé (Togo). Médecine d Afrique Noire, 44, No. 1.

[6] Lund, P.M. (2001) Health and Education of Children with Albinism in Zimbabwe. Health Education Research, 16, 1-7. http://dx.doi.org/10.1093/her/16.1.1

[7] Lookingbill, D.P., Lookingbill, G.L. and Leppard, B. (1995) Actinic Damage and Skin Cancer in Albinos in Northern Tanzania: Findings in 164 Patients Enrolled in an Outreach Skin Care Program. Journal of the American Academy of Dermatology, 32, 653-658. http://dx.doi.org/10.1016/0190-9622(95)90352-6

[8] Mabula, J.B., Chalya, P.L., Mchembe, M.D., Jaka, H. and Giiti, G. (2012) Skin Cancers among Albinos at a University Teaching Hospital in Northwestern Tanzania: A Retrospective Review of 64 Cases. Dermatology, 12, 1-7. http://dx.doi.org/10.1186/1471-5945-12-5

[9] Mahé, E., Longvert, C. and Saiag, P. (2007) Modalités pratiques de photoprotection maximale de l'enfant. Annales de Dermatologie et de Vénéréologie, 134, 4S88-4S91. http://dx.doi.org/10.1016/s0151-9638(07)89255-6

[10] Gautier, M.S. (2008) Tumeurs cutanées avec lésions précancéreuses. In: Encyclopedie Médico- 
Chirurgicale, Elsevier Masson, Paris, Encyclopédie pratique de médecine, 2, 0724, 8 p.

[11] ABIPA (2014) Des consultations et des lunettes pour les albinos des cascades. http://www.aib.bf/m-977-des-consultations-et-des-lunettes-pour-les-albinos-des-cascades.h $\underline{\mathrm{tml}}$

[12] United Nations, Department of Economic and Social Affairs, Population Division. World Population Prospects: The 2015 Revision. Pyramides des âges pour le monde entier de 1950 à 2100. https://populationpyramid.net/fr/burkina-faso/2014/

[13] Centres d'actualités de l'ONU. Les albinos sont des êtres humains comme les autres, rappelle un groupe d'experts de l'ONU. 3 Mai 2013 http://www.un.org/apps/newsFr/storyF.asp?NewsID=30268\#. VziiQORs8to

[14] Greaves, M. (2014) Was Skin Cancer a Selective Force for Black Pigmentation in Early Hominin Evolution? Proceedings. Biological Sciences, 281, 20132955.

[15] Gronskov, K., Ek, J. and Brondum-Nielsen, K. (2007) Oculocutaneous Albinism. Orphanet Journal of Rare Diseases, 2, 43. http://dx.doi.org/10.1186/1750-1172-2-43

[16] Opara, K.O. and Jiburum, B.C. (2010) Skin Cancers in Albinos in a Teaching Hospital in Eastern Nigeria. Presentation and Challenges of Care. World Journal of Surgical Oncology, 8, 1-6.

[17] OMS (1978) Déclaration d'Alma-Ata sur les soins de santé primaires. http://www.who.int/topics/primary_health_care/alma_ata_declaration/fr/

[18] Feldaman, S.R. and Fleischer, A.B. (2000) Skin Examinations and Skin Cancer Prevention Counseling by US Physicians: A Long Way to Go. Journal of the American Academy of Dermatology, 43, 234-237. http://dx.doi.org/10.1067/mjd.2000.105559

[19] Hong, S., Zeeb, H. and Repacholi, M.H. (2006) Albinism in Africa as a Public Health Issue. BMC Public Health, 6, 1-7. http://dx.doi.org/10.1186/1471-2458-6-212 


\section{Survey Sheet}

\section{III-Assessment of Skin Cancer Risk Factors}

1. Have you ever smoked?

a. Yes $\square$ b. No $\square$

2. How many packets do you smoke per year? packet/year

3. Overall, how long did you smoke? $\cdots$ year(s) $\cdots$ month(s)

4. Have you ever been exposed to the sun for a long period?

a. Yes $\square$ b. No

If yes, how long? $\cdots$ hour(s) $\cdots \mathrm{mn}(\mathrm{s})$.

5. Have you ever undergone a radiological examination? a. Yes $\square$ b. No

6. Have you ever worked in a printing company?

a. Yes $\square$ b. No $\square$ If yes, how long? hour(s) mn(s).

7. Have you ever worked in a petrol station or have you ever been in contact for long with fuel or oil ?

a. Yes $\square$ b. No

8. Have you ever been in contact with pesticide?

a. Yes $\square$ b. No

9. Do you have a chronic wound (Chronic ulceration)? a. Yes $\square$ b. No

10. Do you have a hyperpigmented mark on your body? (naevus, beauty spot, Wend bobélé)

a. Yes $\square$ b. No

If yes, for how long do you have it?

11. Are you immunosuppressed (HIV, immunosuppressive treatment)?

a. Yes $\square$ b. No $\square$ c. Does not know

\section{IV-Assessment of Knowledge of Skin Cancer Risk Factors}

Please, answer by yes or no if these factors are skin cancer risk factors or not.

1. Smoke cigarette: True $\square$ False $\square$

2. Long exposure to the sun: True

False $\square$

3. Professional exposure: True $\square$ False

$\square$

4. Cosmetic products containing hydroquinone: True $\square$ False $\square$

5. Albinism: True $\square$ False $\square$

6. Immunodepression (HIV): True

false

7. History of personal skin cancer: True

$\square$ False $\square$

8. Burn scar: True $\square$ False $\square$

9. Chronic wound: True $\square$ False $\square$

10. Hyperpigmented mark: True $\square$ False

$\square$

11. Hypersensitiveness to the sun: True

$\square$ False

\section{V-Knowledge of The Disease}

1. Have you ever heard about skin cancer? a. Yes $\square$ b. No

2. If yes, by what means?

a. The media

b. Health agents $\square$

c. A kin (sister/brother/cousin)

d. A person suffering from cancer

3. Please answer by yes or no to the following questions:

a. A spot, a wound or a dermal mark can be the beginning of a skin cancer: True $\square$ False $\square$

b. Skin cancer is a serious disease: True

False $\square$

c. A contagious disease: True $\square$ False d. A disease that everybody can have: True False $\square$

e. Albinos are the most spared by skin cancer:

True $\square$ False $\square$

f. Albinos are the most exposed to skin cancer:

True $\square$ False
4. What are the symptoms of a beginning cancer a. No sign (asymptomatic) $\square$ b. Pains c. Dermal mark $\square$ d. Spot $\square$ e. Wound $\square$ f. Bleeding of a wound or a skin scar Others

5. The treatment of skin cancer is mostly: a. Medical $\square$ b. Surgical $\square$ others

6. Early detected skin cancer can be cured: True $\square$ False $\square$

7. Lately discovered skin cancer (metastasis) is mortal: True $\square$ False $\square$

\section{VI-Assessment Of The Knowledge Of Screening}

Of Skin Cancer. Answer by True or False:

1. Which people should be screened for skin cancer?

a. Only people with a skin disease

b. Only non-albinos people

c. Albinos also $\square$

d. Everybody $\square$

e. Others

2. When should skin cancer screening be done? a. At any time $\square$ b. When one has a skin lesion

$\square$

3. At what frequency should skin cancer screening be done? a. Anytime when the occasion arises b. Regularly

c. three or four times/year

d. When one has time 


\section{VII- Screening Practices}

1. Have you ever undergone screening for skin cancer?

$$
\text { a. Yes } \square \text { b. No }
$$

If yes, at what age were you screened for the first time?

If YES, at what frequency do you undergo screening?

a. Regularly/according to the advice of health workers $\square$

b. Non-regular screening

c. Once during the diagnosis

d. On the occasion of a consultation for something else $\square$

If yes, where did you undergo it?

a. In a dermatology unit $\square$

b. In an oncology unit

c. In a CSPS

e. In a CMA

2. What rhythm do you consider for a good screening?

a. Every 3 months

b. Every 6 months

c. Once per year for all life

d. Three or four times/year $\square$

3. What motivated you to come to hospital?

a. Referral by a health professional

b. Undesirable symptom

c. The advice of a friend or kin

d. Routine check-up

e. Traditional practitioners

f. Others
4. If $\mathrm{NO}$, what prevents you from coming for screening?

a. The screening centre is far

b. Financial problems

c. I was not sick/I did not have symptoms

d. I did not know screening was existing

e. I did not know where to go for screening

$\square$

f. The fear to discover that one is sick $\square$ g. I did not feel concerned $\square$

2. If you could do something to motivate other albinos to go for screening, what would you do?

a. Advise for the practice of a regular screening $\square$

b. The awareness-raising of the others through associations $\square$

c. Speak of the benefits of screening (more chance to recover if there is early detection; and less devastating treatment)

d. Others
IX-Secondary Prevention

1. Do you know that there are secondary prevention measures? a. Yes $\square$ b. No

If yes, which ones?

2. Do you know about precancerous lesions? a. Yes $\square$ b. No

If yes, what are the precancerous lesions that may turn into skin cancers, according to you

3. The early detection and treatment of precancerous lesions enable avoid that these lesions turn into cancers.

a. True $\square$ b. False $\square$

4. Did you have precancerous lesions before?

a. Yes $\square$ b. No

If yes, since when? $\cdots$ week $(\mathrm{s}) \cdots$ month(s) $\cdots$ year(s)

If yes, were you treated?

a. Yes $\square$ b. No

If yes, Where were you treated?

a. In a $\mathrm{CHU}$

b. In a CHR

c. In a CMA

d. In a CSPS

If yes, by whom?

a. A dermatologist $\square$

b. A medical oncologist c. A general physician

d. A nurse

e. Others

The treatment of this lesion was:

a. Medical $\square$

b. Surgical $\square$

c. Others

What is the evolution after treatment?

a. Good (Complete disappearance of the lesion)

b. Fairly good (Partial disappearance of the lesion)

c. Bad (Persistence of the lesion) 


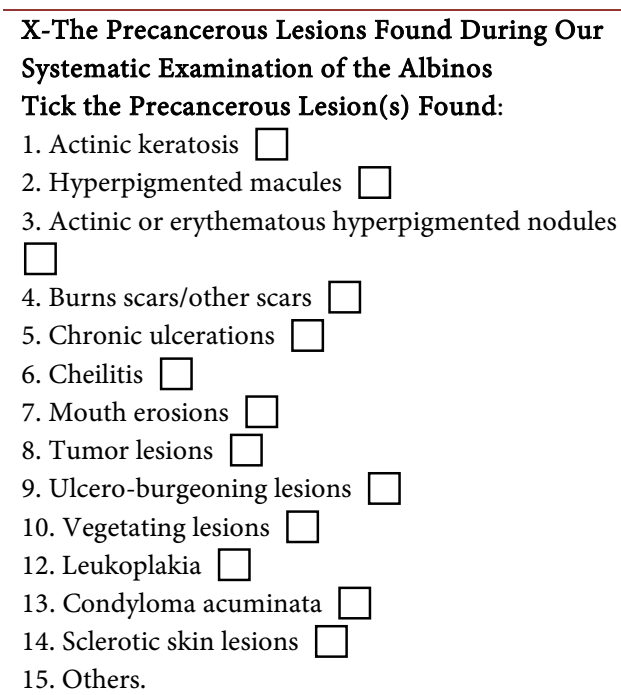

\section{XI-Treatment Proposed According to the Precancerous Lesion Tick the Treatment Proposed for the Pre- cancerous Lesion(s) Found:}

1. Symptomatic treatment:
a. Antiseptic
b. Antibiotic
c. Diclofenac

2. Chemotherapy:

a. 5 fluorouracil

b. Podophyllin

c. Topical cream imiquimod $5 \%$

3.Physical treatment:

a. Electrocoagulation

b. Radiotherapy

c. Cryotherapy

d. Phototherapy

e. Laser $\square$

4. Surgical treatment:

a. Removal

b. Vermillonectomy

c. Curettage, removal by shaving

5. Others

\section{Submit or recommend next manuscript to SCIRP and we will provide best service} for you:

Accepting pre-submission inquiries through Email, Facebook, LinkedIn, Twitter, etc.

A wide selection of journals (inclusive of 9 subjects, more than 200 journals)

Providing 24-hour high-quality service

User-friendly online submission system

Fair and swift peer-review system

Efficient typesetting and proofreading procedure

Display of the result of downloads and visits, as well as the number of cited articles

Maximum dissemination of your research work

Submit your manuscript at: http://papersubmission.scirp.org/

Or contact jet@scirp.org 